\title{
Biosensing Amplification by Hybridization Chain Reaction on Phase-Sensitive Surface Plasmon Resonance
}

\author{
Ching-Hsu Yang ${ }^{1}$, Tzu-Heng Wu ${ }^{1}$, Chia-Chen Chang ${ }^{2,3} \mathbb{D}$, Hui-Yun Lo ${ }^{4}$, Hui-Wen Liu ${ }^{4}$, Nien-Tsu Huang ${ }^{1,5, * \mathbb{D}}$ \\ and Chii-Wann Lin 4,5,6,*
}

1 Graduate Institute of Biomedical Electronics and Bioinformatics, National Taiwan University, Taipei 106, Taiwan; d02945009@ntu.edu.tw (C.-H.Y.); aresation@gmail.com (T.-H.W.)

2 Department of Medical Biotechnology and Laboratory Sciences, College of Medicine, Chang Gung University, Taoyuan 333, Taiwan; chang@mail.cgu.edu.tw

3 Kidney Research Center, Department of Nephrology, Chang Gung Memorial Hospital, Taoyuan 333, Taiwan

4 Department of Biomedical Engineering, National Taiwan University, Taipei 106, Taiwan; onlyby1231@gmail.com (H.-Y.L.); k8006780067@yahoo.com.tw (H.-W.L.)

5 Department of Electrical Engineering, National Taiwan University, Taipei 106, Taiwan

6 Biomedical Technology and Device Research Laboratories, Industrial Technology Research Institute, Hsinchu 310, Taiwan

* Correspondence: nthuang@ntu.edu.tw (N.-T.H.); cwlinx@ntu.edu.tw (C.-W.L.)

Citation: Yang, C.-H.; Wu, T.-H.; Chang, C.-C.; Lo, H.-Y.; Liu, H.-W.; Huang, N.-T.; Lin, C.-W. Biosensing Amplification by Hybridization Chain Reaction on Phase-Sensitive Surface Plasmon Resonance. Biosensors 2021, 11, 75. https:// doi.org/10.3390/bios11030075

Received: 11 February 2021

Accepted: 2 March 2021

Published: 6 March 2021

Publisher's Note: MDPI stays neutral with regard to jurisdictional claims in published maps and institutional affiliations.

Copyright: (c) 2021 by the authors. Licensee MDPI, Basel, Switzerland. This article is an open access article distributed under the terms and conditions of the Creative Commons Attribution (CC BY) license (https:// creativecommons.org/licenses/by/ $4.0 /)$.

\begin{abstract}
Surface Plasmon Resonance (SPR) is widely used in biological and chemical sensing with fascinating properties. However, the application of SPR to detect trace targets is hampered by nonspecific binding and poor signal. A variety of approaches for amplification have been explored to overcome this deficiency including DNA aptamers as versatile target detection tools. Hybridization chain reaction (HCR) is a high-efficiency enzyme-free DNA amplification method operated at room temperature, in which two stable species of DNA hairpins coexist in solution until the introduction of the initiator strand triggers a cascade of hybridization events. At an optimal salt condition, as the concentrations of $\mathrm{H} 1$ and $\mathrm{H} 2$ increased, the HCR signals were enhanced, leading to signal amplification reaching up to 6.5 -fold of the detection measure at $30 \mathrm{~min}$. This feature enables DNA to act as an amplifying transducer for biosensing applications to provide an enzyme-free alternative that can easily detect complex DNA sequences. Improvement of more diverse recognition events can be achieved by integrating HCR with a phase-sensitive SPR (pSPR)-tested aptamer stimulus. This work seeks to establish pSPR aptamer system for highly informative sensing by means of an amplification HCR. Thus, combining PSPR and HCR technologies provide an expandable platform for sensitive biosensing.
\end{abstract}

Keywords: aptamer; hybridization chain reaction; phase-sensitive surface plasmon resonance (pSPR) biosensor

\section{Introduction}

The Surface Plasmon Resonance (SPR) biosensor is based on an electromagnetic wave that oscillates between the metallic film and the dielectric plate. The adsorption measurement on metal surfaces or metal nanoparticles (gold or silver) is based on SPR. Several color-dependent biosensor systems and different lab-on-chip sensors are key components. SPR is capable of performing real-time, label-free and high-sensitivity monitoring of molecular interactions and is now a leading technology for biomolecular target detection $[1,2]$. SPR has been employed for the detection of nucleic acids [3,4], proteins [5,6] and small molecules [4], by measuring the reflective index change during complex formation or dissociation $[7,8]$. However, the application of SPR to detect trace targets, particularly in complex biological samples, is hampered by non-specific binding and poor signal. A variety of approaches for amplification to support better detection have been explored to overcome this deficiency [6]. According to the operating principles, SPR biosensors can 
be divided into angle-, wavelength-, intensity- and phase-sensitive devices. With their complex optical configurations, pSPR sensors generally provide higher sensitivity and throughput, and have thus recently emerged as prominent biosensing devices [9]. pSPR is more sensitive than intensity-based SPR since the limit of detection (LOD) of pSPR is around $10^{-7}$ RIU, while the LOD of intensity-based SPR is at the $10^{-5}$ RIU scale [10,11]. In special designed and custom developed instrumentations, the SPR enables the detection of DNA targets down to the femtomolar range or lower $[12,13]$.

Nucleic acid amplification methodologies have drawn significant research efforts for effective identification, as nucleic acids are regularly assessed to assist in biological experiments, molecular analysis and biomedical application. Therefore, the recognition of nucleic acids requires a powerful biosensor. A number of SPR studies were developed aiming for the incorporation of appropriate signal enhancement methods to determine complex conditions [14-16].

DNA aptamers are DNA sequences that bind to a certain protein screened by exponential enrichment systematic ligand evolution (SELEX) [17]. Aptamers have several advantages such as small size, versatile structure, strong binding affinity, high stability and good biocompatibility that has led to broad applications in the biomedical field [18]. Due to their simplicity and the ability to be easily modified and applied to different fields, aptamerbased SPR biosensors have been used to detect DNA [18], protein [19,20], nanoparticle [21], small molecules [22] and microRNA [23]. Compared with the conventional methods and other sensing strategies, this aptamer-based SPR biosensor system has several advantages such as faster, simpler, lower-cost, more practical, and better stability [24]. The proposed aptamer-based SPR biosensor could detect HIV-related DNA sensitively and specifically with a wide linear range from $1 \mathrm{pM}$ to $150 \mathrm{nM}$ and a detection limit of $48 \mathrm{fM}$, which is promising for the point-of-care detection of HIV infections [25]. Due to their simplicity and the ability to be easily modified and applied to different fields, the use of aptamer-based SPR biosensors can be a sensitive technique to improve the accuracy and correctness of measurements. However, the amplitude of signal detection is often unsatisfactory and requires continuous improvement to better meet the need for clinical applications [26].

Hybridization Chain Reaction (HCR) is a high-efficiency enzyme-free DNA amplification process operated at room temperature in which two stable species of DNA hairpins coexist in solution until a cascade of hybridization events is triggered by the introduction of the initiator strand [27]. Nonlinear HCR is considered to be a powerful signal amplifier for the detection of biomarkers through integration with flexible sensing platforms, given the benefits of its enzyme-free, high-order kinetic growth, high sensitivity, and simple procedure [28]. We introduce the methodology of HCR in which stable DNA monomers assemble only when exposed to a target DNA fragment.

The method of HCR has been applied to the detection of COVID-19. The technique is to provide a screening tool for isothermal amplification, a better screening strategy to prevent on-going epidemics. The chain reactions targeted Severe Acute Respiratory Syndrome coronavirus 2 (SARS-CoV-2) complementary DNA (cDNA) with loci corresponding to the gold standard of polymerase chain reaction (PCR) loci. The loop domain of the fuel hairpin molecules as optimization parameters, $\mathrm{H} 1$ and $\mathrm{H} 2$, the tunable segments in such responses, are used to enhance the hybridization efficiency. HCR reactions of the algorithm-derived with gel electrophoresis were validated. All proposed reactions show a hybridization complex with $>1.5 \mathrm{k}$ base pair molecular mass, which is clear evidence of a chain reaction. The trend shown by gel electrophoresis corresponds nicely to the algorithm's simulated data. The HCR reactions and the corresponding algorithm form the basis for further sensing of SARS-CoV-2 [29]. Recently, usage of SPR in detection of SARS-CoV-2 has made significant progress [30-33]. However, the combination of SPR and HCR for the detection of SARS-CoV-2 has not been studied.

This paper describes a technique based on a chain reaction between three sets of DNA aptamer molecules for amplification, providing an enzyme-free alternative that can easily detect complex DNA sequences. HCR is performed to combine the platform of SPR signal 
detection as a simple implementable add-on technique that enables the increase in signal detection sensitivity. Improvement of more diverse recognition events can be achieved by integrating HCR with pSPR-tested aptamer stimuli. This feature enables DNA to act as an amplifying transducer for biosensing applications to establish a pSPR aptamer system for highly informative sensing by means of an amplification HCR.

\section{Materials and Methods}

\subsection{Phase-Sensitive Surface Plasmon Resonance ( $p S P R$ )}

The working principle is Heterodyne Interferometry, to obtain interference, a YVO4 birefringent crystal was adopted. Analysis of the related parameters affecting the efficiency of light coupling to the silicon waveguide's Vertical-Cavity Surface-Emitting Laser (VCSEL, Philips ULM-852-BS-PL-S46FZP) with emission wavelength of $852 \mathrm{~nm}$ and a power of $2 \mathrm{~mW}$ is operated under a protection circuit with a $300 \mathrm{ohm}$ resistance. This $852 \mathrm{~nm}$ light propagates along the vertical direction into the birefringent crystal, and p-polarization and s-polarization rays exhibit different optical path lengths (OPD) and subsequently shift in phase relative to one another. To accurately distinguish detection from the background signal, the thermal drift issue was subtracted by adding a reference arm, where light passes a beam splitter. The other part of the laser light goes to the fluidic system. Phase modulation was yielded by direct current modulation on VCSEL [9]. The residual amplitude modulation (RAM) issue was dealt with using the Generalized Lock-In Amplifier algorithm (GLIA), a method previously published by our group to establish a band-pass filter in GLIA to exclude out-of-band noise and to improve the signal-to-noise ratio [34]. The SPR sensor chip is composed of a $49 \mathrm{~nm}$ gold plasmonic layer and a $2 \mathrm{~nm}$ chromium adhesion layer on BK-7 glass. The thickness of the gold layer is chosen to optimize the sensitivity of the phase detection.

The gold films were deposited by an electron beam evaporator at a vacuum level of approximately $3 \times 10^{-6}$ Torr [35]. The deposition was $0.2 \AA / \mathrm{s}$. To elucidate the sensitivity of the SPR sensor chips, angle-resolved phase spectra were measured and fitted with Fresnel's multilayer reflection model (Figure 1). The efficacy of the system was built first to estimate the wavelength-to-current sensitivity factor (S) value, which is intrinsic to the nature of individual VCSEL; we determined a specific current modulation that is needed to achieve $\Delta^{\prime \prime}=3.8317$. The feasibility of the pSPR system through fringe image and SPR image was at the Krestchmann angle. To accurately distinguish the DNA measurement signal, thermal drift was subtracted by adding a reference arm. Then, with glucose solution for sensitivity calibration, a Limit-of Detection (LOD) of $7.5 \times 10^{-7}$ RIU was demonstrated where noise was estimated to be around $0.0004 \mathrm{rad}$. Using this system, a detection of target DNA down to $50 \mathrm{nM}$ can be reached.

In order to obtain the interference of light, a birefringent crystal (BC) was used. The laser light propagates along the vertical direction into $\mathrm{BC}$, and p-polarization and s-polarization rays exhibit different optical path lengths (OPD) and are subsequently shifted in phase relative to one another. To accurately distinguish the detection signal from the background signal, the thermal drift was subtracted by adding a reference arm, where light passes a beam splitter (BS). The other part of the laser light goes to the fluidic chip, where PSPR measurements could be done. 


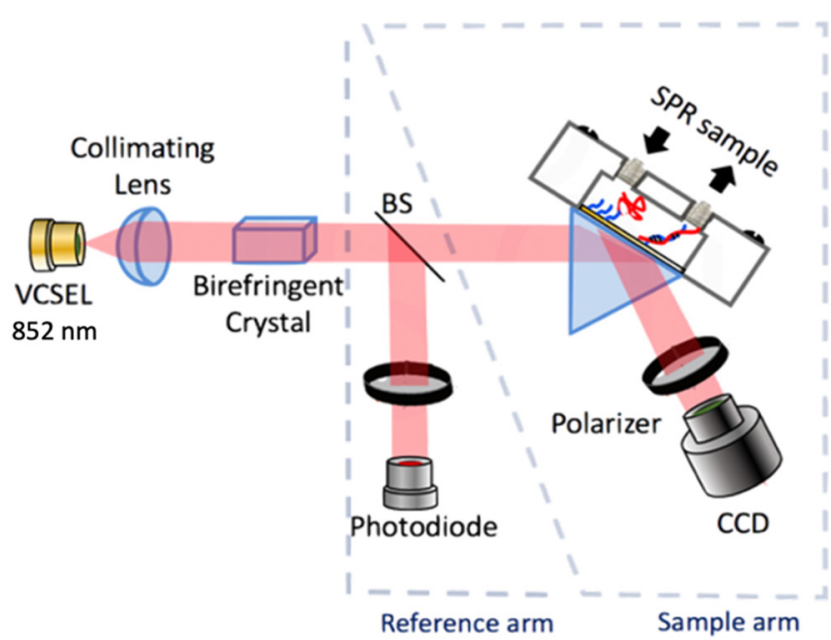

(A) The Optical System of pSPR

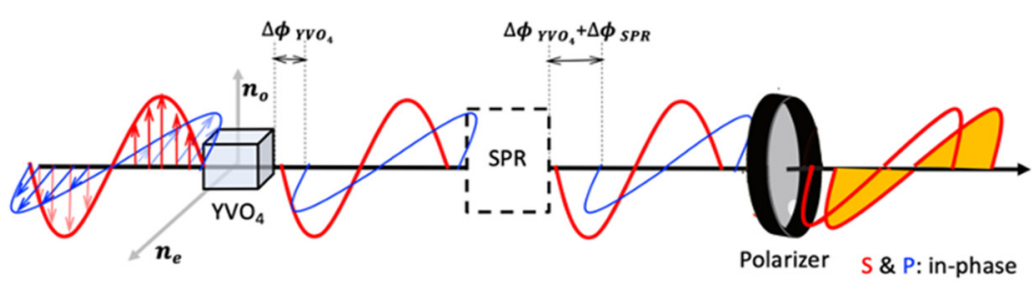

(B) Wavefront Division of Birefringent Crystal (BC)

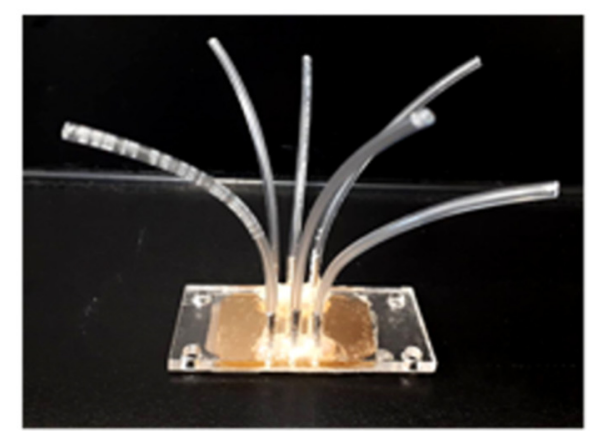

(C)SPR chip $2 \mathrm{~nm} \mathrm{Cr}+49 \mathrm{~nm} \mathrm{Au}$

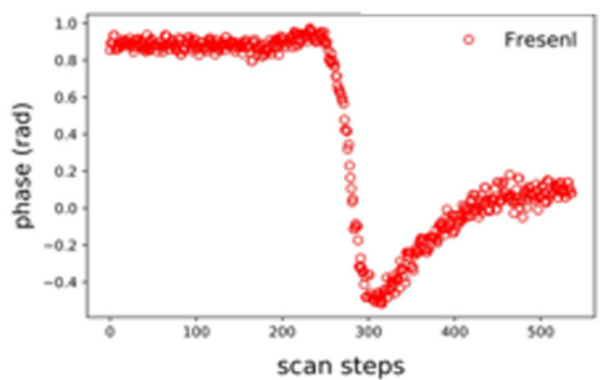

(D) Phase-sensitive SPR (red)

Figure 1. (A) Setup of the phase-sensitive surface plasmon resonance (pSPR) system. (B) Wavefront division of the birefringent crystal. (C) SPR chip. (D) Phase-sensitive SPR scan steps.

\subsection{DNA Aptamers}

The DNA aptamer oligonucleotides were synthesized and purified by HPLC at Purigo Biotech, Inc. (Taipei, Taiwan), and their sequences are listed in Table 1. A stock solution of the thiol-modified hairpin probe was prepared in a $10 \mathrm{mM}$ Tris- $\mathrm{HCl}$ buffer solution $(\mathrm{pH} 8)$ containing $1 \mathrm{M} \mathrm{NaCl}$ and $0.1 \mathrm{M} \mathrm{MgCl}_{2}$. These chemicals were obtained from Sigma-Aldrich (St. Louis, MO, USA). All DNA stock solutions were stored at $4{ }^{\circ} \mathrm{C}$ to prevent degradation.

Table 1. Sequence of the DNA aptamers used in this research.

\begin{tabular}{lr}
\hline Aptamer Sequence $\left(\mathbf{5}^{\prime} \rightarrow \mathbf{3}^{\prime}\right)$ & \\
\hline $\begin{array}{l}\text { Initiator } \\
\text { (thiolated-10T }+22 \text { mer })\end{array}$ & HS-TTTTTTTTTTACGCACGGTCTTAAGTTGATAC \\
H1 (44 mer) & GTATCAACTTAAGACCGTGCGTTATATCACGCACGGTCTTAAGT \\
H2 (44 mer) & ACGCACGGTCTTAAGTTGATACACTTAAGACCGTGCGTGATATA \\
\hline
\end{tabular}

The folding of the DNA initiator and two hairpins was predicted using Nupack (available at http:/ /www.nupack.org/, accessed on 9 October 2020) (Figure 2) [17]. We used cancer metastasis exosome Integrin $\alpha 6 \beta 4$ biomarker to validate and implement the HCR-based SPR-Biosensor and as the positive control for the experiment [36,37]. 
(A)

\section{HCR sequence design}

Initiator

Hairpin 1

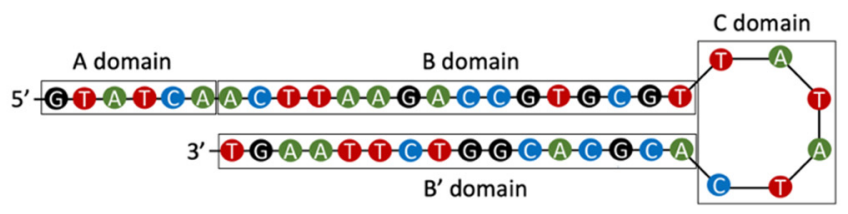

Hairpin 2

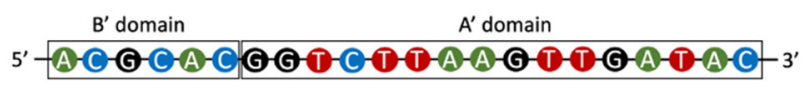

(B)

\section{NUPACK simulation}

A
$:$ C
$:$ G
$-T$

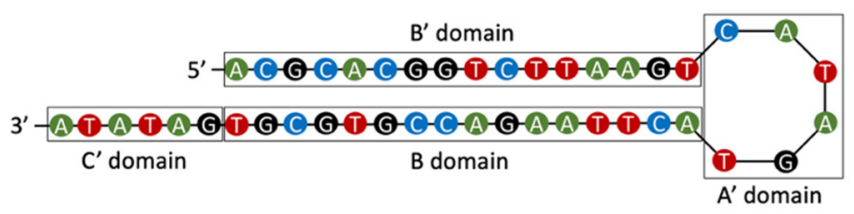

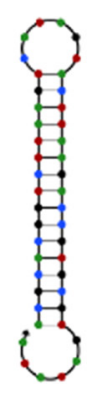

$\underset{c}{\because c}$

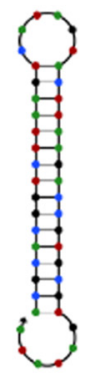

$: A$
$: c$
$:$ G
T

Figure 2. The design of three DNA aptamers that exhibit HCR signal amplification capabilities. (A) Schematic illustration of the HCR-pSPR detection aptamers. (B) Simulative schematics of the bare aptamer and the coupling DNA modified aptamer.

\subsection{HCR on $p S P R$ with Pre-Immobilized Initiator Probe}

The procedure of probe immobilization and target hybridization was done first to anneal a gold film surface with deionized water to avoid non-specific binding and $20 \mathrm{mM}$ 6-mercapto-1-hexanol (MCH) (Sigma-Aldrich, St. Louis, MO, USA) to minimize generation of a secondary structure. Then, $1 \mathrm{uM}$ initiator probe DNA was added for $1 \mathrm{~h}$ for a higher density of immobilization. Again, the gold film surface was cleaned with deionized water to further reduce non-specific binding. With the probe immobilized, DNA hybridization can then be measured by the pSPR system.

We designed HCR sequences and anchored $1 \mu \mathrm{M} 5$ '-end thiolated-initiator and $10 \mathrm{nM}$ thiolated-10 thymine on the gold surface of the pSPR chip, and then introduced $1 \mu \mathrm{M}$ of $\mathrm{H} 1$. Later, a mixture of $1 \mu \mathrm{M} \mathrm{H} 1$ and $\mathrm{H} 2$ was injected to enable HCR reaction. As the initiator was bound by $\mathrm{H} 1$, forming an initiator-H1 complex, $\mathrm{H} 2$ was then combined to the $\mathrm{H} 1$ tail, and $\mathrm{H} 1$ and $\mathrm{H} 2$ were bounded alternatively and repeatedly to form a double helix DNA complex structure, leading to signal amplification (Figure 3). A gradient of sodium chloride was injected into the fluid system as a calibration ruler for data normalization. After the definition of a working angle, signals of self-assembly were captured by a Charge-coupled Device camera and recorded for analysis. 


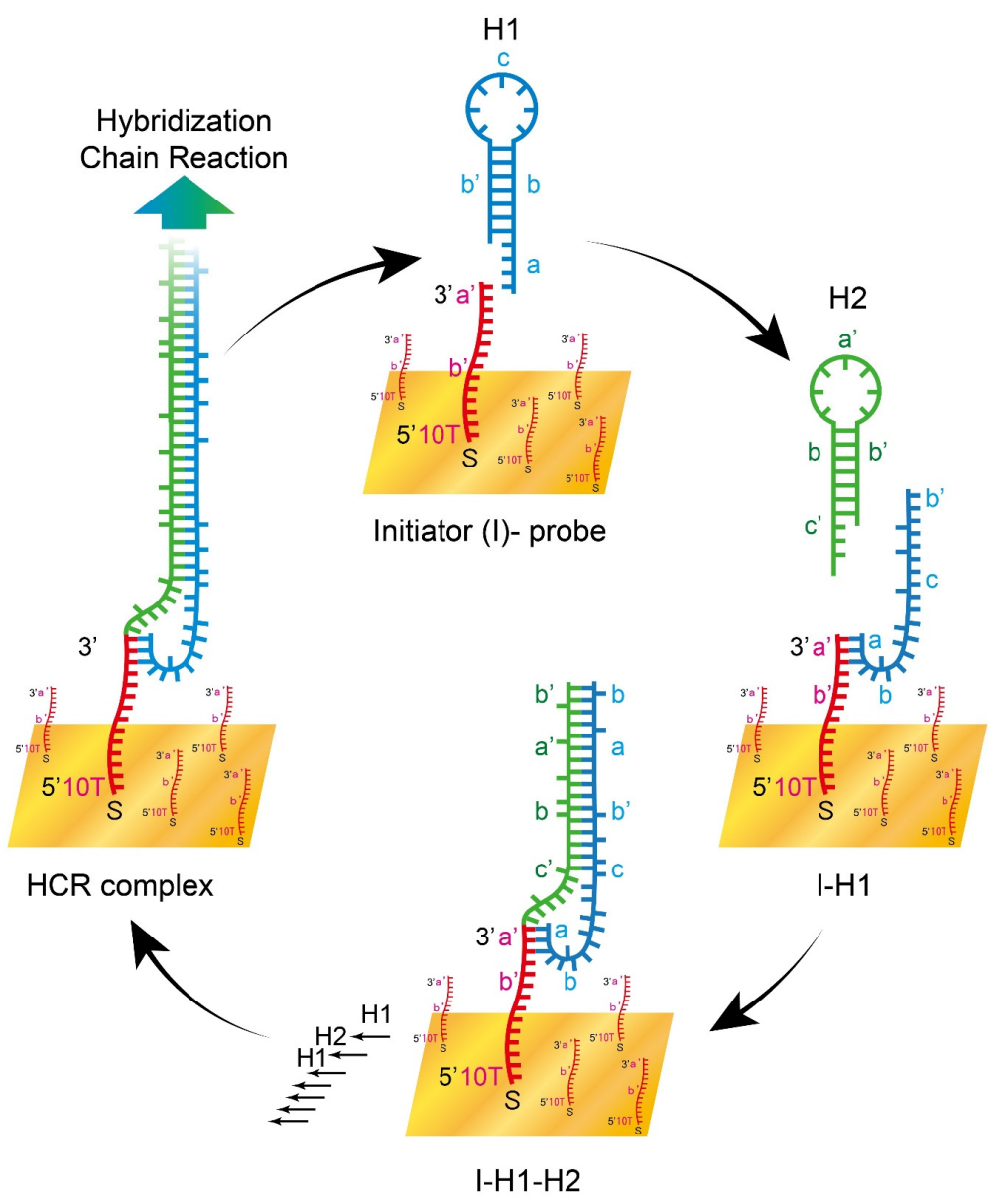

Figure 3. Schematic illustration of the HCR-pSPR self-assembly on gold surface detection platform.

\subsection{DNA Gel Electrophoresis}

To verify the initiator, $\mathrm{H} 1$ and $\mathrm{H} 2$ DNA aptamers underwent HCR amplification. The $2 \%$ agarose gel electrophoresis experiment was performed in $1 \times$ sodium borate buffer $(1 \times$ SB buffer) (Sigma-Aldrich, St. Louis, MO, USA). Electrophoresis was done with a $100 \mathrm{~V}$ driving voltage (with MAJOR SCIENCE MP-100) at room temperature, using a $1 \times$ SB running buffer. The fluorescent dye used for imaging was Safe Green (Hycell, Taipei, Taiwan). The proportion of initiator, $\mathrm{H} 1$ and $\mathrm{H} 2$ was 5:5:0.25 to 5:5:10, and after 30 min of mixing, the HCR yield was from $100 \mathrm{bp}$ to $2 \mathrm{kbp}$. In the gel electrophoresis experiment, the HCR chemistry was in free solution, the proportion of initiator, H1 and H2 was 5:5:0.25 to 5:5:10, while in pSPR, the initiator was anchored on a gold surface, a two-dimensional space with 10 mer Thymine spacers in between.

\section{Results}

\subsection{Validation of HCR on $p S P R$ with Pre-Immobilized Initiator Probe}

We anchored the HCR initiator DNA aptamer on the SPR chip gold surface and added $\mathrm{H} 1$ and $\mathrm{H} 2$ sequences to amplify the HCR signal. A gradient of sodium chloride, $0.025 \mathrm{M} \mathrm{NaCl}, 0.05 \mathrm{M} \mathrm{NaCl}, 0.1 \mathrm{M} \mathrm{NaCl}$ and $0.2 \mathrm{M} \mathrm{NaCl}$ was injected into the fluidic system to become a calibration ruler for data normalization. Running buffer $(1 \times \mathrm{PBS}+1 \mathrm{MNaCl})$ was added to gain the baseline. At around 5000 s, $500 \mathrm{nM} \mathrm{H} 1$ was injected to form the H1-initiator complex. After one hour, running buffer was added to stop the reaction; the reaction was around $0.0001 \Delta$ RIU. We then added $1 \mu \mathrm{M}$ mixture of $\mathrm{H} 1$ and $\mathrm{H} 2$ to the system. As can be seen, the HCR reaction was around $0.0005 \triangle \mathrm{RIU}$ at $30 \mathrm{~min}$. In the pSPR result, after $30 \mathrm{~min}$ of the initiator and $\mathrm{H} 1$ binding reaction and the $30 \mathrm{~min}$ washing step marks $\mathrm{A}$, the time point of 30 min after the addition of $\mathrm{H} 1$ and $\mathrm{H} 2$ mixture marks $\mathrm{B} .(\mathrm{A}+\mathrm{B}) / \mathrm{A}=6.5$, 
indicating a 6.5 -fold of the detection measure at $30 \mathrm{~min}$. There was no significant signal difference when only $\mathrm{H} 1$ was added (Figure $4 \mathrm{~A}$ ).

(A)

(B)

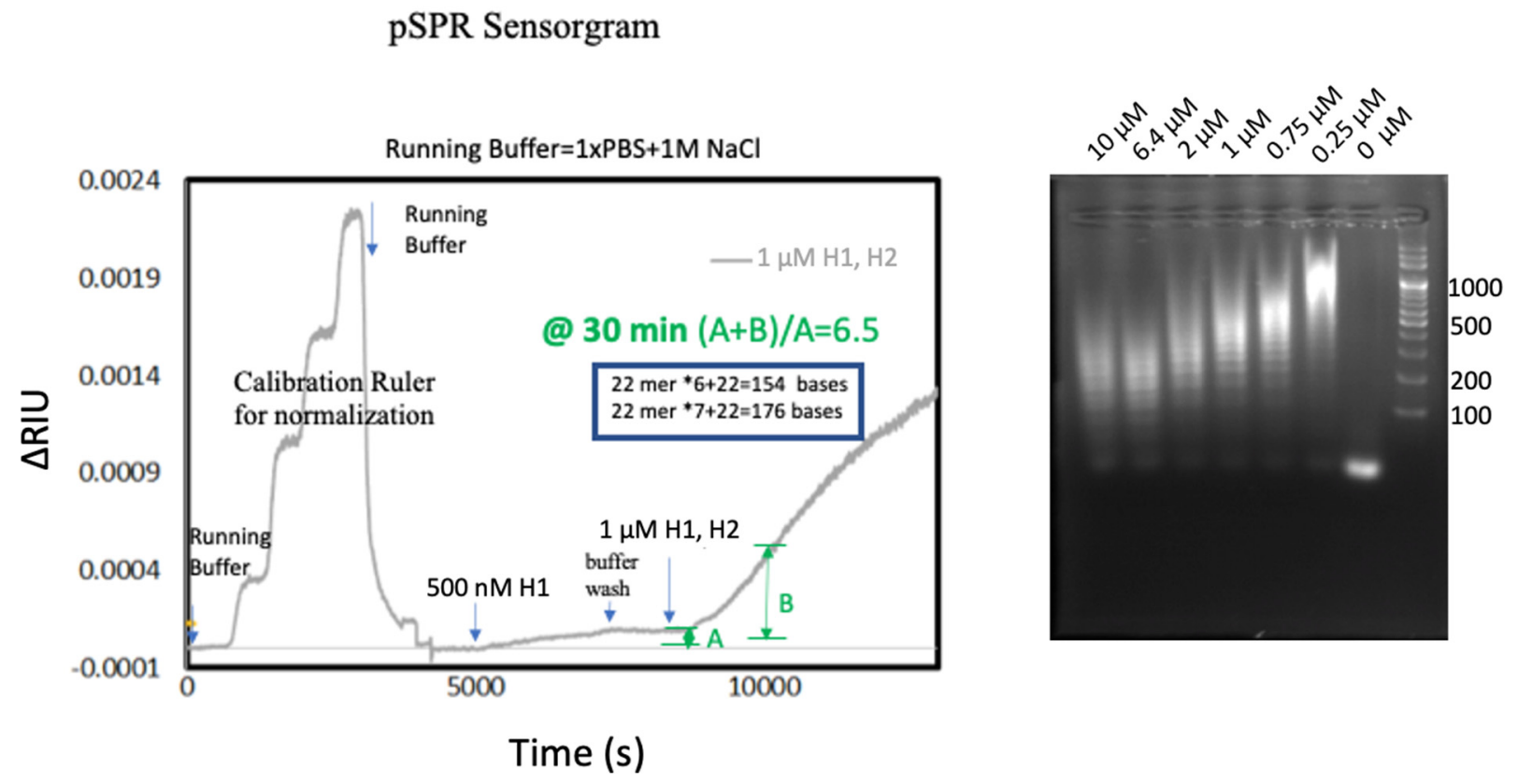

Figure 4. (A) Real-time detection of the HCR reaction. In the pSPR result, after 30 min of the initiator and H1 binding reaction and the 30 min washing step marks $\mathrm{A}$, the time point of $30 \mathrm{~min}$ after the addition of the $\mathrm{H} 1$ and $\mathrm{H} 2$ mixture marks $\mathrm{B}$. $(\mathrm{A}+\mathrm{B}) / \mathrm{A}=6.5$, indicating a 6.5 -fold of the detection measure at $30 \mathrm{~min}$. (B) Combining pSPR and DNA gel electrophoresis results. The length of the HCR complex at the same reaction time, $30 \mathrm{~min}$, can be observed.

\subsection{Combining $p S P R$ and DNA Gel Electrophoresis}

By combining PSPR and DNA gel electrophoresis results, we were able to study the length of HCR product at the same reaction time of $30 \mathrm{~min}$. We also compared the product length of HCR at $60 \mathrm{~min}$, by pSPR and DNA gel electrophoresis. Initiator was $22+10 \mathrm{~T}=32 \mathrm{mer}$, but only 22 mer reacted in the HCR process. H1 and H2 each had 44 mer, the combination of H1 and H2 makes $22+22=44,22 \times 6+22=154$ bases, $22 \times 7+22=176$ bases (Figure 4B).

\subsection{The Effect of Aptamer and Salt Concentration on HCR Amplification}

Results of HCR reaction under different aptamer concentrations and ionic strength environment are shown in Figure 5. The results showed that the concentrations of H1, H2 and the subsequent HCR amplification were in direct proportion: while the concentrations of $\mathrm{H} 1$ and $\mathrm{H} 2$ increased, HCR amplification increased (Figure 5A). In this set of experiments, the initiator probe was fixed on the SPR chip gold surface. The chip was then set for sensing under changing salt concentrations. As shown in Figure 5, the baseline was established using a running buffer. After the baseline was established, $\mathrm{H} 1+\mathrm{H} 2$ mixture samples were then injected into the microfluidic channel for sensing. At around $700 \mathrm{~s}, \mathrm{H} 1+\mathrm{H} 2$ mixture samples arrived. Upon sample arrival, pSPR rising signals were observed corresponding to different experimental conditions. In order to validate the effect of salt concentration, HCR was undertaken under 1.0, 1.5 and $2.0 \mathrm{M} \mathrm{NaCl}$ in $1 \times \mathrm{PBS}$. As can be seen, the $\mathrm{HCR}$ reaction was most intense under a running buffer composition of $1.5 \mathrm{M} \mathrm{NaCl}$ in $1 \times \mathrm{PBS}$. Based on the data, the HCR reaction was relatively smaller under salt concentrations higher or lower than $1.5 \mathrm{M} \mathrm{NaCl}$ in $1 \times$ PBS (Figure 5B). Therefore, we concluded that there is an optimized salt concentration for surface-based HCR. 


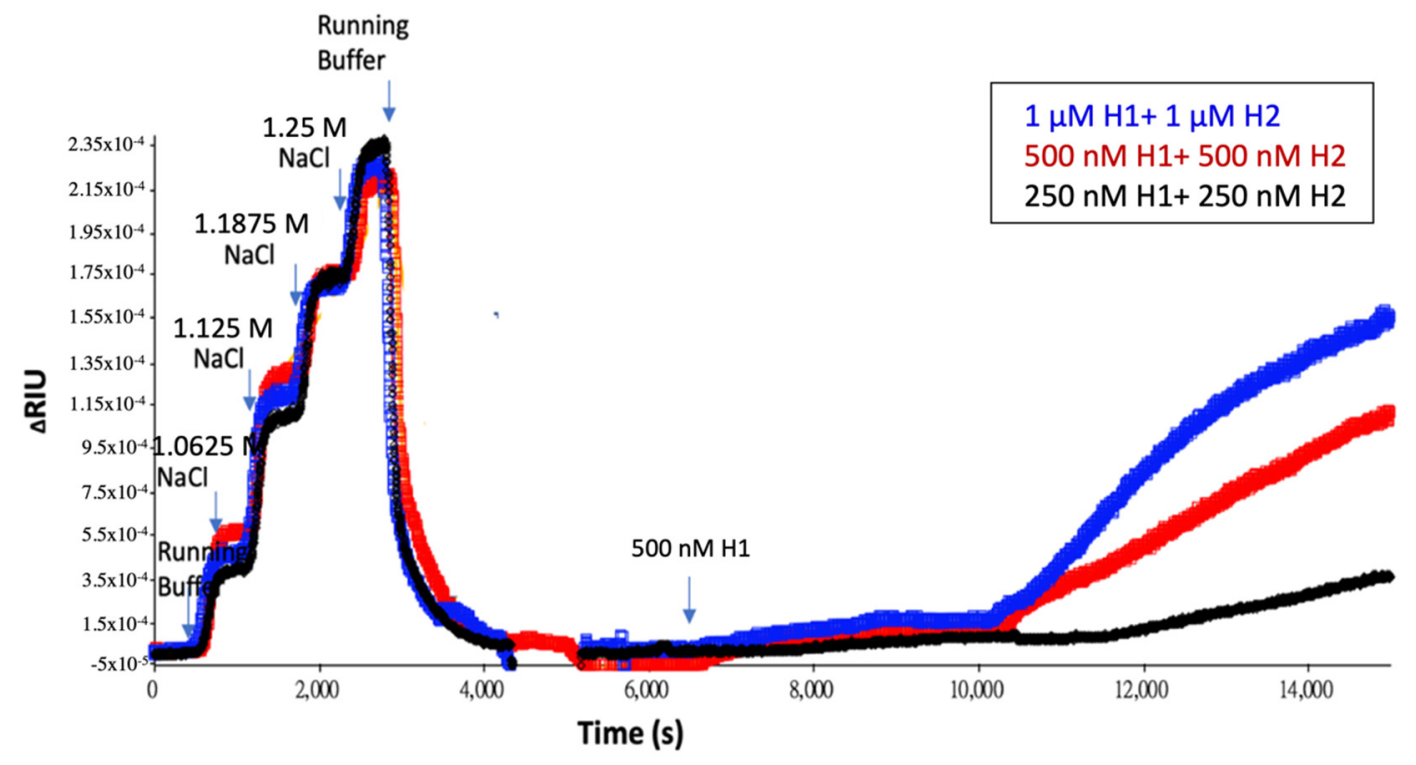

(A)

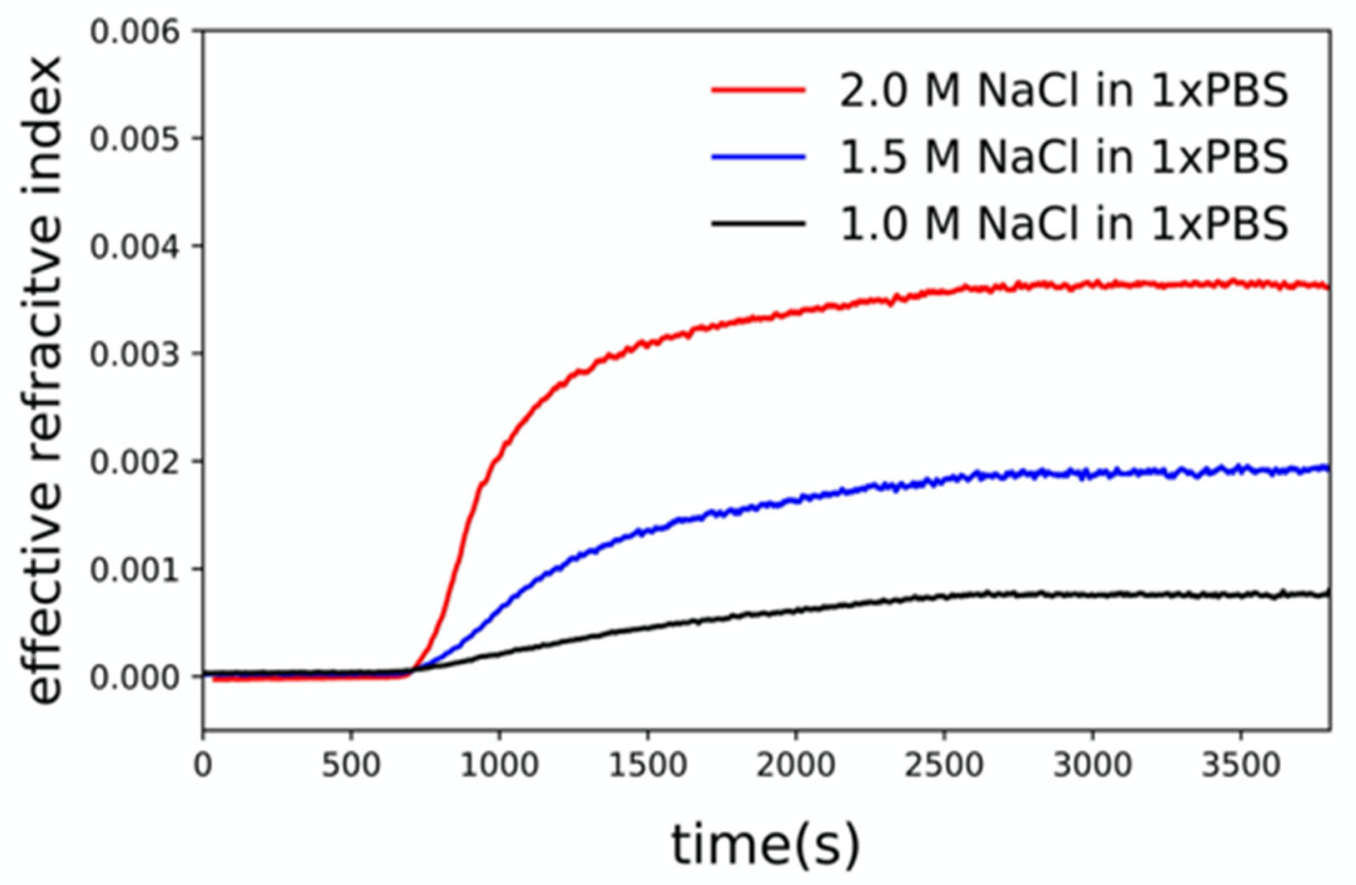

(B)

Figure 5. Result of HCR reaction under different aptamer concentrations and ionic strength environments. (A) The concentration of $\mathrm{H} 1, \mathrm{H} 2$ and the subsequent $\mathrm{HCR}$ amplification are in direct proportion: while the concentration of $\mathrm{H} 1$ and $\mathrm{H} 2$ increases, HCR amplification increases. Blue: $1 \mu \mathrm{M} \mathrm{H} 1+1 \mu \mathrm{M} \mathrm{H} 2$, Red: $500 \mathrm{nM} \mathrm{H} 1+500 \mathrm{nM} \mathrm{H} 2$ and Black: $250 \mathrm{nM} \mathrm{H1}+250 \mathrm{nM} \mathrm{H} 2$. (B) Validation of salt concentration of HCR on pSPR with pre-immobilized initiator probe; $1.0 \mathrm{M}$, $1.5 \mathrm{M}$ and $2.0 \mathrm{M} \mathrm{NaCl}$ in $1 \times$ PBS were added with $1 \mu \mathrm{M} \mathrm{H} 1$ and $\mathrm{H} 2$ mixture at $400 \mathrm{~s}$, and injected $1 \times$ PBS buffer at $2530 \mathrm{~s}$. Three HCR reactions showed $0.0007,0.0018$ and 0.0036 in $\triangle$ RIU indicating different salt concentrations affected HCR amplification results. 


\section{Discussion}

In the present work, a pSPR detection system based on HCR was developed for the amplification of DNA aptamers. We designed HCR sequences and anchored the $5^{\prime}$-end thiolated-10 thymine-initiator on the gold surface of the pSPR chip, and then we introduced $\mathrm{H} 1$ and $\mathrm{H} 2$ hairpin DNA aptamers to enable HCR reaction. As the initiator was bound by $\mathrm{H} 1$, forming an initiator-H1 complex, $\mathrm{H} 2$ was then combined to the $\mathrm{H} 1$ tail, and the $\mathrm{H} 1$ and $\mathrm{H} 2$ were bounded alternatively and repeatedly to form a double-helix DNA complex structure without an enzyme. Finally, as the concentration of $\mathrm{H} 1$ and $\mathrm{H} 2$ increased, the HCR signals were enhanced, leading to signal amplification.

The HCR chemistry was in free solution in the gel electrophoresis experiment. The proportion of initiator, $\mathrm{H} 1$ and $\mathrm{H} 2$ was 5:5:0.25 to 5:5:10, while the initiator was anchored on the gold surface in pSPR, a two-dimensional space with 10 mer adenosine spacers in between.

We designed HCR sequences, planted thiolated-initiator on the gold surface of the pSPR chip, and then introduced H1 and H2 to enable HCR. On the other hand, when thiolated H1 was first bound to the gold surface, HCR could not be activated followed by adding initiator and $\mathrm{H} 2$ in our setting. This is because the initiator is needed initially when the hairpin structure is unlocked, and the structure of HCR-initiator can be revealed and opened for the HCR reaction.

The HCR response was most intense under a running buffer composition of $1.5 \mathrm{M}$ $\mathrm{NaCl}$ in $1 \times \mathrm{PBS}$, as can be seen. Based on the data, at salt concentrations greater than or less than $1.5 \mathrm{M} \mathrm{NaCl}$ in $1 \times \mathrm{PBS}$, the $\mathrm{HCR}$ reaction was relatively smaller. We therefore conclude that, for pSPR-based HCR, there is an optimal salt concentration.

Loop-mediated isothermal amplification (LAMP) has also observed these phenomena [38-42]. This effect was the result, according to the authors, of an optimal salt concentration. Therefore, the salt concentration must be optimized to achieve maximum sensitivity when applying HCR reactions for diagnostic purposes. Recent studies have demonstrated the usefulness of the sequence specimen during genetic detection by combining LAMP with one stage stream displacement (OSD) [43]. However, because OSD is unable to provide signal amplification, the signal-to-noise ratio or the observed signals may not be significant as to satisfy practical use. In order to meet this challenge, a more advanced sensing principle has been developed to replace OSD with HCR. The highly contagious norovirus (NoV) was used as a model target to achieve more reliable detection. Compared to LAMP-OSD, LAMP-HCR can detect as few as 30 copies of the NoV gene in fecal samples with significantly increased signal amplification and a signal-to-background ratio [43]. Furthermore, because of the high compatibility of HCR, the final LAMP-HCR products can be flexibly transduced into different types of readings. In the future, combination techniques of pSPR and LAMP-HCR can be further evaluated in order to expand the detection to a higher tolerance for complicated biological materials.

In a previous study using microfluidics, higher SPR signals could be obtained with target concentrations from $10 \mathrm{nM}$ to $100 \mathrm{nM}$ where target signals can be detectable prior to HCR [12]. During HCR in the SPR microfluidics, a relatively quick steady-state can be reached. Signal flattening is reached at concentrations higher than $100 \mathrm{nM}$ due to surface saturation enabled by the efficient SPR microfluidics used for target hybridization. These data demonstrate that performing HCR does decrease the detection limit for the bound target. Thus, when using higher-performance SPR equipment and microfluidics HCR combination [13], it is reasonable to expect that the limit of detection could reach far below the nanomolar level.

A recent advance of pSPR has been proposed to combine amplification cascades of catalyzed hairpin assembly (CHA) and HCR with the sensitive SPR responses of plasmonic gold nanorods [23]. The proposed bioassay exhibited ultrahigh sensitivity toward tested miRNA with dynamic range from $5.0 \times 10^{-17} \mathrm{M}$ to $1.0 \times 10^{-11} \mathrm{M}$.

Thus, the method of combining PSPR and HCR technologies provides an expandable platform for future direction of ultrasensitive biosensing. 


\section{Conclusions}

$\mathrm{HCR}$ is a high-efficiency enzyme-free DNA amplification process operated at room temperature, in which two stable species of DNA hairpins coexist in solution before the introduction of the initiator strand causes a cascade of hybridization events. Improvement of more diverse recognition events can be achieved by integrating HCR with pSPR-tested aptamer stimuli. This feature enables DNA to act as an amplifying transducer for biosensing applications. This work sets out a pSPR system for highly informative sensing using HCR for amplification and opens a new era of sensitive detection for various biological and medical conditions for pSPR biosensor technology. Possible future applications may include early diagnosis of cancer metastases, prognosis prediction and exosome profiling by tumor marker quantification.

Author Contributions: Conceptualization, C.-W.L., T.-H.W. and C.-H.Y.; methodology, T.-H.W., C.-H.Y.; software, T.-H.W.; validation, C.-W.L., T.-H.W., C.-H.Y., H.-Y.L. and H.-W.L.; formal analysis, C.-H.Y., T.-H.W.; investigation, H.-Y.L. and H.-W.L.; resources, C.-C.C., T.-H.W.; data curation, C.-C.C., T.-H.W.; writing-original draft preparation, C.-H.Y., T.-H.W., C.-C.C.; writing-review and editing, C.-H.Y.; visualization, C.-H.Y., C.-C.C.; supervision, N.-T.H., C.-W.L.; project administration, T.-H.W.; funding acquisition, C.-W.L. All authors have read and agreed to the published version of the manuscript.

Funding: This study was funded by a grant from the Ministry of Science and Technology (MOST 109-2221-E-002-189-MY3) to C.-W. Lin.

Institutional Review Board Statement: Not applicable.

Informed Consent Statement: Not applicable.

Data Availability Statement: Not applicable.

Acknowledgments: The authors wish to thank Ingrid Kuo and the Center for Big Data Analytics and Statistics (Grant CLRPG3D0047) at Chang Gung Memorial Hospital for creating Figure 3 for the illustration used herein.

Conflicts of Interest: The authors declare no conflict of interest.

\section{References}

1. Homola, J. Surface plasmon resonance sensors for detection of chemical and biological species. Chem. Rev. 2008, 108, 462-493. [CrossRef]

2. Wark, A.W.; Lee, H.J.; Corn, R.M. Multiplexed detection methods for profiling microRNA expression in biological samples. Angew. Chem. Int. Ed. 2008, 47, 644-652. [CrossRef] [PubMed]

3. He, L.; Musick, M.D.; Nicewarner, S.R.; Salinas, F.G.; Benkovic, S.J.; Natan, M.J.; Keating, C.D. Colloidal Au-Enhanced Surface Plasmon Resonance for Ultrasensitive Detection of DNA Hybridization. J. Am. Chem. Soc. 2000, 122, 9071-9077. [CrossRef]

4. Zhang, Z.; Cheng, Q.; Feng, P. Selective removal of DNA-labeled nanoparticles from planar substrates by DNA displacement reactions. Angew. Chem. Int. Ed. 2009, 48, 118-122. [CrossRef]

5. Yi, X.; Hao, Y.; Ning, X.; Wang, J.; Quintero, M.; Li, D.; Zhou, F. Sensitive and continuous screening of inhibitors of $\beta$-site amyloid precursor protein cleaving enzyme 1 (BACE1) at single SPR chips. Anal. Chem. 2013, 85, 3660-3666. [CrossRef]

6. Bai, Y.; Feng, F.; Zhao, L.; Wang, C.; Wang, H.; Tian, M.; Qin, J.; Duan, Y.; He, X. Aptamer/thrombin/aptamer-AuNPs sandwich enhanced surface plasmon resonance sensor for the detection of subnanomolar thrombin. Biosens. Bioelectron. 2013, 47, 265-270. [CrossRef]

7. Rich, R.L.; Myszka, D.G. Advances in surface plasmon resonance biosensor analysis. Curr. Opin. Biotechnol. 2000, 11, 54-61. [CrossRef]

8. Li, X.; Wang, Y.; Wang, L.; Wei, Q. A surface plasmon resonance assay coupled with a hybridization chain reaction for amplified detection of DNA and small molecules. Chem. Commun. 2014, 50, 5049-5052. [CrossRef] [PubMed]

9. Deng, S.; Wang, P.; Yu, X. Phase-Sensitive Surface Plasmon Resonance Sensors: Recent Progress and Future Prospects. Sensors 2017, 17, 2819. [CrossRef]

10. Nelson, S.G.; Johnston, K.S.; Yee, S.S. High sensitivity surface plasmon resonace sensor based on phase detection. Sens. Actuators B Chem. 1996, 35, 187-191. [CrossRef]

11. Kabashin, A.V.; Patskovsky, S.; Grigorenko, A.N. Phase and amplitude sensitivities in surface plasmon resonance bio and chemical sensing. Opt. Express 2009, 17, 21191-21204. [CrossRef] 
12. Spiga, F.M.; Bonyár, A.; Ring, B.; Onofri, M.; Vinelli, A.; Sántha, H.; Guiducci, C.; Zuccheri, G. Hybridization chain reaction performed on a metal surface as a means of signal amplification in SPR and electrochemical biosensors. Biosens. Bioelectron. 2014, 54, 102-108. [CrossRef]

13. Luan, Q.; Xue, Y.; Yao, X. A simple hairpin DNA sensor for label-free detection of sub-attomole DNA target. Sens. Actuators B Chem. 2010, 147, 561-565. [CrossRef]

14. Gorodkiewicz, E.; Lukaszewski, Z. Recent Progress in Surface Plasmon Resonance Biosensors (2016 to Mid-2018). Biosensors 2018, 8, 132. [CrossRef] [PubMed]

15. Nguyen, H.H.; Park, J.; Kang, S.; Kim, M. Surface plasmon resonance: A versatile technique for biosensor applications. Sensors 2015, 15, 10481-10510. [CrossRef] [PubMed]

16. Šípová, H.; Homola, J. Surface plasmon resonance sensing of nucleic acids: A review. Anal. Chim. Acta 2013, 773, 9-23. [CrossRef] [PubMed]

17. Zadeh, J.N.; Steenberg, C.D.; Bois, J.S.; Wolfe, B.R.; Pierce, M.B.; Khan, A.R.; Dirks, R.M.; Pierce, N.A. NUPACK: Analysis and design of nucleic acid systems. J. Comput. Chem. 2011, 32, 170-173. [CrossRef]

18. Cai, S.; Yan, J.; Xiong, H.; Liu, Y.; Peng, D.; Liu, Z. Investigations on the interface of nucleic acid aptamers and binding targets. Analyst 2018, 143, 5317-5338. [CrossRef] [PubMed]

19. Lorenzo-Gómez, R.; Fernández-Alonso, N.; Miranda-Castro, R.; de-los-Santos-Álvarez, N.; Lobo-Castañón, M.J. Unravelling the lipocalin 2 interaction with aptamers: May rolling circle amplification improve their functional affinity? Talanta 2019, 197, 406-412. [CrossRef] [PubMed]

20. Sun, W.; Song, W.; Guo, X.; Wang, Z. Ultrasensitive detection of nucleic acids and proteins using quartz crystal microbalance and surface plasmon resonance sensors based on target-triggering multiple signal amplification strategy. Anal. Chim. Acta 2017, 978, 42-47. [CrossRef] [PubMed]

21. Fathi, F.; Rashidi, M.-R.; Omidi, Y. Ultra-sensitive detection by metal nanoparticles-mediated enhanced SPR biosensors. Talanta 2019, 192, 118-127. [CrossRef]

22. Li, Q.; Wang, Q.; Yang, X.; Wang, K.; Zhang, H.; Nie, W. High sensitivity surface plasmon resonance biosensor for detection of microRNA and small molecule based on graphene oxide-gold nanoparticles composites. Talanta 2017, 174, 521-526. [CrossRef] [PubMed]

23. Gu, Y.; Song, J.; Li, M.X.; Zhang, T.T.; Zhao, W.; Xu, J.J.; Liu, M.; Chen, H.Y. Ultrasensitive MicroRNA Assay via Surface Plasmon Resonance Responses of Au@Ag Nanorods Etching. Anal. Chem. 2017, 89, 10585-10591. [CrossRef]

24. Wang, C.; Liu, M.; Wang, Z.; Li, S.; Deng, Y.; He, N. Point-of-care diagnostics for infectious diseases: From methods to devices. Nano Today 2021, 37, 101092. [CrossRef] [PubMed]

25. Diao, W.; Tang, M.; Ding, S.; Li, X.; Cheng, W.; Mo, F.; Yan, X.; Ma, H.; Yan, Y. Highly sensitive surface plasmon resonance biosensor for the detection of HIV-related DNA based on dynamic and structural DNA nanodevices. Biosens. Bioelectron. 2018, 100, 228-234. [CrossRef] [PubMed]

26. Falkowski, P.; Lukaszewski, Z.; Gorodkiewicz, E. Potential of surface plasmon resonance biosensors in cancer detection. J. Pharm. Biomed. Anal. 2021, 194, 113802. [CrossRef]

27. Dirks, R.M.; Pierce, N.A. Triggered amplification by hybridization chain reaction. Proc. Natl. Acad. Sci. USA 2004, 101, 15275-15278. [CrossRef]

28. Bi, S.; Yue, S.; Zhang, S. Hybridization chain reaction: A versatile molecular tool for biosensing, bioimaging, and biomedicine. Chem. Soc. Rev. 2017, 46, 4281-4298. [CrossRef]

29. Wu, T.-H.; Chang, C.-C.; Yang, C.-H.; Lin, W.-Y.; Ee, T.J.; Lin, C.-W. Hybridization Chain Reactions Targeting the Severe Acute Respiratory Syndrome Coronavirus 2 (SARS-CoV-2). Int. J. Mol. Sci. 2020, 21, 3216. [CrossRef]

30. Abid, S.A.; Suhail, A.; Al-Kadmy, I.M.S.; Sattar, A.A.; Beshbishy, A.M.; Batiha, G.E.; Hetta, H.F. Biosensors as a future diagnostic approach for COVID-19. Life Sci. 2021, 119117. [CrossRef]

31. Du, A.; Zheng, R.; Disoma, C.; Li, S.; Chen, Z.; Li, S.; Liu, P.; Zhou, Y.; Shen, Y.; Liu, S.; et al. Epigallocatechin-3-gallate, an active ingredient of Traditional Chinese Medicines, inhibits the 3CLpro activity of SARS-CoV-2. Int. J. Biol. Macromol. 2021, 176, 1-12. [CrossRef]

32. Yokoyama, K.; Ichiki, A. Nano-size dependence in the adsorption by the SARS-CoV-2 spike protein over gold colloid. Colloids Surf. A Physicochem. Eng. Asp. 2021, 615, 126275. [CrossRef]

33. Yokoyama, K.; Ichiki, A. Spectroscopic investigation on the affinity of SARS-CoV-2 spike protein to gold nano-particles. Colloid Interface Sci. Commun. 2021, 40, 100356. [CrossRef]

34. Wu, T.-H.; Chang, C.-C.; Vaillant, J.; Bruyant, A.; Lin, C.-W. DNA biosensor combining single-wavelength colorimetry and a digital lock-in amplifier within a smartphone. Lab Chip 2016, 16, 4527-4533. [CrossRef]

35. Liang, Y.H.; Chang, C.C.; Chen, C.C.; Chu-Su, Y.; Lin, C.W. Development of an Au/ZnO thin film surface plasmon resonancebased biosensor immunoassay for the detection of carbohydrate antigen 15-3 in human saliva. Clin. Biochem. 2012, 45, 1689-1693. [CrossRef]

36. Hoshino, A.; Costa-Silva, B.; Shen, T.L.; Rodrigues, G.; Hashimoto, A.; Mark, M.T.; Molina, H.; Kohsaka, S.; Di Giannatale, A.; Ceder, S.; et al. Tumour exosome integrins determine organotropic metastasis. Nature 2015, 527, 329-335. [CrossRef] [PubMed]

37. Wang, H.; Rana, S.; Giese, N.; Büchler, M.W.; Zöller, M. Tspan8, CD44v6 and $\alpha 6 \beta 4$ are biomarkers of migrating pancreatic cancer-initiating cells. Int. J. Cancer 2013, 133, 416-426. [CrossRef] 
38. Chang, C.C.; Lin, S.; Lee, C.H.; Chuang, T.L.; Hsueh, P.R.; Lai, H.C.; Lin, C.W. Amplified surface plasmon resonance immunosensor for interferon-gamma based on a streptavidin-incorporated aptamer. Biosens. Bioelectron. 2012, 37, 68-74. [CrossRef] [PubMed]

39. Suebsing, R.; Prombun, P.; Kiatpathomchai, W. Reverse transcription loop-mediated isothermal amplification (RT-LAMP) combined with colorimetric gold nanoparticle (AuNP) probe assay for visual detection of Penaeus vannamei nodavirus (Pv NV). Lett. Appl. Microbiol. 2013, 56, 428-435. [CrossRef]

40. Podushkina, D.; West, N.W.; Golenberg, E.M. Utilizing multiplex fluor LAMPs to illuminate multiple gene expressions in situ. PLoS ONE 2019, 14, e0223333. [CrossRef] [PubMed]

41. Gantt, S.; Goldfarb, D.M.; Park, A.; Rawlinson, W.; Boppana, S.B.; Lazzarotto, T.; Mertz, L.M. Performance of the Alethia CMV Assay for Detection of Cytomegalovirus by Use of Neonatal Saliva Swabs. J. Clin. Microbiol. 2020, 58. [CrossRef] [PubMed]

42. Tehrani, B.S.; Mirzajani, E.; Fallahi, S.; Naeini, K.M.; Mahmoudi, M.R.; Kavishahi, M.S.; Eskandari, V.; Zebardast, N. Challenging TaqMan probe-based real-time PCR and loop-mediated isothermal amplification (LAMP): The two sensitive molecular techniques for the detection of toxoplasmosis, a potentially dangerous opportunistic infection in immunocompromised patients. Arch. Microbiol. 2020, 202, 1881-1888. [CrossRef] [PubMed]

43. Chen, C.; Ridzon, D.A.; Broomer, A.J.; Zhou, Z.; Lee, D.H.; Nguyen, J.T.; Barbisin, M.; Xu, N.L.; Mahuvakar, V.R.; Andersen, M.R.; et al. Real-time quantification of microRNAs by stem-loop RT-PCR. Nucleic Acids Res. 2005, 33, e179. [CrossRef] [PubMed] 